\title{
A Língua dos Karuãnas
}

The Language of the Karuãnas

Erdeson dos Santos Vilhena

Universidade Federal do Amapá ${ }^{1}$

Resumo. Este estudo tem como objetivo mostrar alguns aspectos do pensamento indígena a partir da interpretação intercultural do conhecimento sobre a poética indígena (sobre o "fazer bonito"). Nesse sentido, utilizaremos caminhos diferentes para explorarmos a afirmação de que a formalidade, no sentido adotado neste trabalho, está muito ligada às línguas dos karuãna. Tentaremos explicar alguns aspectos da arte verbal Karipuna através do pota do Redemoinho. Para isso, fizemos uma tradução literal de cada uma das palavras. É importante dizer que os potas, em geral, são executados em Galibi Antigo (Kalinã, em outro estágio diacrônico), e misturam palavras de outras línguas. Em seguida, partimos para uma tradução simbólica do pota, onde buscamos fazer a relação entre os personagens e o contexto de uso de cada um dos pota. Outras questões mais gerais mais profundas são desenvolvidas com o pajé, o Senhor Martinho Júnior Damasceno, de 33 anos.

Palavras-Chave: Karipuna. Pota. Rezas. Línguas Indígenas do Amapá.

Abstract. This paper aims to show some aspects of indigenous thought using to this intercultural interpretation of knowledge about indigenous poetics (about "doing beautiful"). In this sense, we use different paths to explore the claim that formality, in the sense adopted in the paper, is closely linked to the languages of the Karuãna. We are involved to explain some aspects of the Karipuna verbal art through the Pota do Redemoinho. For this, we made a literal translation of each of the words that compose it. In general, it is important to say that potas are executed in Old Galibi (Kalinã, in another diachronic stage), and it is constituted of a mix of words from different languages. Finally, we present on the paper a symbolic translation of the potá, in which we observe the relationship between the characters and the context of use of each potá

Keywords: Karipuna. Pota. Prays. Indigenous Language of Amapá.

\section{Introdução}

Esta introdução está dividida em 3 partes. Na primeira, damos algumas explicações sobre como foi o processo de transformar e ou transmitir um saber que é de natureza oral, explicado e transmitido de maneira oral para uma forma escrita acadêmica. Na segunda parte, o leitor vai conhecer melhor sobre como consideramos o conceito de gênero narrativo dentro dos estudos das artes verbais indígenas. Também é na segunda parte que expomos os principais objetivos desse trabalho, que é, em resumo, mostrar alguns aspectos do pensamento indígena a partir da interpretação intercultural do conhecimento sobre a poética indígena (sobre o "fazer bonito"). Argumentamos que a forma é central e exploramos essa ideia. Na terceira parte da introdução damos informações sobre povo, território, língua e sociedade dos Karipuna da Terra Indígena do Uaçá.

1 Graduando da Licenciatura Intercultural Indígena, Universidade Federal do Amapá (Campus Binacional). 
1.1. Sobre a forma de pensar e escrever este trabalho de conclusão de curso: uma explicação sobre a forma de explicar 'não-Ocidental'

Ao escrever este trabalho levei comigo o mais profundo respeito e consideração pela tradição oral do meu povo Karipuna. Para o processo de escrita, estudo e reflexão foram levadas em consideração as obras Lang dji pota-iela (A língua dos pota) de Janina dos Santos Forte (2017), que é indígena do povo Karipuna. Nesse trabalho, Forte (2017) documenta e apresenta os potas, uma forma de expressão verbal que faz parte da performance de um tipo de reza tradicional. Também utilizamos como ponto de partida o texto Forma e significado na poética oral kuikuro de Bruna Franchetto (1989), um ensaio que propõe algumas categorias para a poética oral kuikuro com base em uma metodologia básica de análise de natureza ocidental (do branco). Outros autores também serviram de embasamento inicial para o desenvolvimento deste trabalho.

Além de contar com as fontes na parte acadêmica tradicional, tive uma fonte de saber riquíssima através do pajé da minha aldeia para a construção de meu trabalho. A participação do Senhor Martinho Damasceno foi de importância fundamental no compartilhamento de seu conhecimento com o sobrenatural. Através dele pude registrar cantos no celular e junto com ele fazer a tradução, identificação e origem de algumas palavras. Com os cantos que eram executados e gravados foram feitas interpretações de como são organizados a estrutura desses cantos e em qual momento e contexto serão usados esses versos. O objetivo principal foi comentar, a partir da expressão das artes verbais Karipuna, o pensamento indígena.

\subsection{Gêneros narrativos indígenas e o objetivo deste trabalho}

Os gêneros narrativos indígenas têm formas, estilos e estruturas que podem ser definidas a partir de modelos que estudem a diferença entre o formal e o informal (FRANCHETTO, 1989). A formalidade, em todas as suas partes, conteúdo e execução, é o traço mais saliente e que pode nos dar ideias interessantes sobre como se organizam os gêneros narrativos indígenas. Através de uma análise que junta a tradição clássica considerada ocidental greco-latina, de analisar forma e função (segundo a Arte Poética de Aristóteles), com pensamentos da filosofia indígena professada pelo pajé entrevistado, buscamos compreender um pouco da poética verbal Karipuna em sua formalidade. A formalidade na poética indígena Karipuna pode ser considerada algo como um fenômeno estético ou 'feito para ser bonito'.

Os gêneros narrativos orais indígenas utilizam-se de certos recursos, como o emprego de repetições, sejam musicais ou metafóricas, algo puramente de dimensão formal (FRANCHETTO, 1989). Contexto e função são dimensões muito importantes para entendermos de forma mais completa os gêneros narrativos orais indígenas, mas não serão o foco deste trabalho. Neste trabalho, o foco será a formalidade da expressão da poética indígena. Para isso, olharemos para alguns exemplos da poética Karipuna².

\footnotetext{
${ }^{2}$ O povo Karipuna, a que pertence o autor deste artigo, habita a Terra Indígena no Uaçá, município do Oiapoque, Estado do Amapá, Brasil.
} 
Os gêneros narrativos Karipuna voltados às atividades do pajé ou à comunicação com os 'espíritos' (karuãna), como os pota (fórmulas de cura), em geral, possuem estruturas consideradas mais rígidas, repetitivas e cantadas, em contraste à fala normal e cotidiana das pessoas que não são espíritos. Por isso, esse gênero discursivo pode ser umas das línguas dos Karuãna. Os karuãna só entendem gêneros narrativos que se parecem mais com músicas e cantos do que com fala normal.

Neste trabalho, utilizaremos caminhos diferentes para explorarmos a afirmação de que a formalidade, no sentido que a adotamos, está muito ligada às línguas dos karuãna. Tentaremos explicar alguns aspectos da arte verbal Karipuna através do pota do Redemoinho ${ }^{3}$. Para isso, fizemos uma tradução literal de cada uma das palavras. É importante dizer que os pota, em geral, são executados em Galibi Antigo (Kalinã, em outro estágio diacrônico), e misturam palavras de outras línguas. Em seguida, partimos para uma tradução simbólica do pota, em que buscamos fazer a relação entre os personagens e o contexto de uso de cada um dos pota. Outras questões mais gerais mais profundas são desenvolvidas com o pajé, o Senhor Martinho Júnior Damasceno, de 33 anos. Na próxima seção apresentamos um breve histórico do Uaçá, a região onde os Karipuna habitam.

\subsection{Histórico da região do Uaçá}

Em uma extensa área no município de Oiapoque, extremo norte do Estado do Amapá, na Região Norte do Brasil, localiza-se a Terra Indígena Uaçá, homologada no mês de outubro do ano de 1991, através do Decreto n. 298/1991, publicado no Diário Oficial da União, com uma vasta área estimada em 470.164 hectares e com uma população de 7.000 indígenas. Nessa imensa região vivem três povos indígenas, Karipuna, Palikur e Galibi-Marworno.

Os Karipuna vivem em sua grande maioria em 4 aldeias maiores, Manga, Santa Isabel, Espirito Santo e Açaizal, e em 11 aldeias menores, Japim, Zacarias, Mõbak, Benuá, Bastiõ, Paxiuabal, Pakapuá, Txipidõ, Taminã, Kubahi e Jõdef, às margens do rio Curipi, 6 aldeias ao longo da BR-156, Estrela, Ahumã, Kariá, Kuripi, Piquiá e Palha, e, ainda, 2 aldeias, Kunanã e Ariramba, às margens do rio Oiapoque, na Terra Indígena Juminã ${ }^{4}$. Entre nós karipuna há duas línguas faladas, o kheóul karipuna e o português

Segundo o depoimento de Manoel Primo dos Santos, publicado no livro Povos Indígenas no Brasil (RICARDO, 1983, p. 69):

Os Karipuna vieram do baixo Amazonas de embarcação a vela, eram civilizados, e não vieram pelas matas, vieram uns 200 , entre crianças e adultos, fugidos dos cabanos. Vieram pra cá porque aqui era território contestado, não era propriamente Brasil. Entraram no rio Oiapoque até que vieram explorar o rio Curipi a cima e ficaram lá no lugar chamado cemitério, chamado assim porque morreram muitos índios Karipunas. Quem tinha morado aqui eram os Palikur, mas depois, com a guerra de índio com índio (Galibi) se afasttaram para o Urucauá e aqui tinha ficado vazio. Depois foi entrando civilizado pelo meio e desapareceram, mas a origem é Karipuna. Quando eu era mais novo eu via ainda dançar a kuiapuranga, eles falam o Tupi-Guarani, a língua geral. Meus tios davam os nomes dos karipuna tudinho que vieram naquela época. Daí vieram os palikur, entraram em contato, os galibi do kumarumã entraram em contato e vieram civilizados, como veio a família dos Santos. Meu avô era do município de Vigia no Pará, a Familia Fortes veio de Abaetetuba e tiveram outros. Naquele tempo vinha pro norte quem tinha feito alguma coisa pra lá. Aqui

\footnotetext{
${ }^{3}$ Refere-se ao redemoinho que ocorre na superfície dos rios.

${ }^{4}$ Terra Indígena contígua a Terra indígena Uaçá. 
era esconderijo dos brasileiros que faziam qualquer besteira por lá. Corriam pra cá no meio dos índios. Meu avô era dos Santos, casado com karipuna. Os Fortes também casaram com karipuna. E de lá pra cá a gente vem levando essa mistura. Quando quer casar pra lá pro kumarumã, vai e casa e pronto, fica pra lá. Quando quer vir pra cá vem. [...]

Os Galibi-Marworno também vivem na Terra Indigena Uaçá em uma aldeia grande, Kumarumã, que concentra a maior parte dessa etnia, e em aldeias menores que foram criadas recentemente no alto rio Uaçá. Os Galibi são falantes também do Kheuól em sua variante GalibiMarworno. Os Galibi-Marworno, segundo seus pesquisadores, indígenas e não- indígenas, e antigos moradores explicam que este povo se formou a partir da mistura de várias etnias indígenas, principalmente Maraon, que são citados por viajantes da região do Oiapoque desde o século XVII, e os Aruã, oriundos da ilha de Marajó que migraram no século XVIII em fuga das perseguições e explorações dos portugueses (IEPÉ, 2017).

Os Palikur vivem compartilhadamente na Terra Indigena Uaçá, com os povos Karipuna e Galibi-Marworno. Estão localizados no alto rio Urucuá em uma aldeia grande, Kumenê, que também concentra a maior parte da população, e há outras aldeias menores no rio Urucauá e aldeias palikur situadas ao longo da BR-156. Os Palikur é o povo mais antigo com registros sobre sua existência na região do Uaçá. Há registros antigos sobre os Palikur que aparecem nos relatos do navegador espanhol Vicente Yanez Pinzon, em 1513, sob o nome Parikura, e em outros escritos históricos e etnológicos sobre a origem e designação deste povo (GALLOIS; GRUPIONI, 2003). Os Palikur são falantes da língua Parikwaki, língua do tronco linguístico Arawak (SILVA, 2016).

Dentro de nossa cultura existem seres além do humano, que consideramos perigosos quando são desrespeitados e como também podem fazer o bem. Existem vários seres sobrenaturais ligados a natureza presentes em todos os lugares. Entre esses seres há aqueles causadores de boas ações, como até a cura de algumas doenças e também provocar sérios problemas de saúde física e espiritual. 0 que faz os três povos da região terem essa relação em comum a gêneros orais são os seus muitos versos de cantos que utilizam para ter essa comunicação direta com o sobrenatural. Essa comunicação é feita através de estruturas e palavras nos seus versos a origem da língua que são utilizadas nos mesmos. Assim, em um canto Karipuna pode parecer palavras de origem Galibi ou até Palikur. Há também outras formas orais que são realizadas através de rezas que podem ser de forma assobiada, cantada ou murmuradas em tons bem baixinhos que às vezes se tornam difíceis de entender e são executadas tanto pelo pajé como por pessoas que tenham o profundo conhecimento delas.

\section{Os cantos relacionados ao pajé}

Para nós Karipuna, os cantos relacionados ao pajé podem ser executados de três formas: pelo assobio, pelo murmúrio ou pelo assopro. Cada uma das formas é entoada em momentos diferentes pelo pajé durante o xitoto. Podemos dizer que o xitoto é o evento em que ocorrem as cantarolas com o objetivo de diagnosticar o paciente que se encontra enfermo por doenças causadas por seres sobrenaturais. Um xitoto pode envolver várias pessoas, como o palika, que é o seu ajudante. O palika assume, momentaneamente, as funções do pajé, em uma espécie de intermediário entre o pajé e o público que participa do xitoto. 


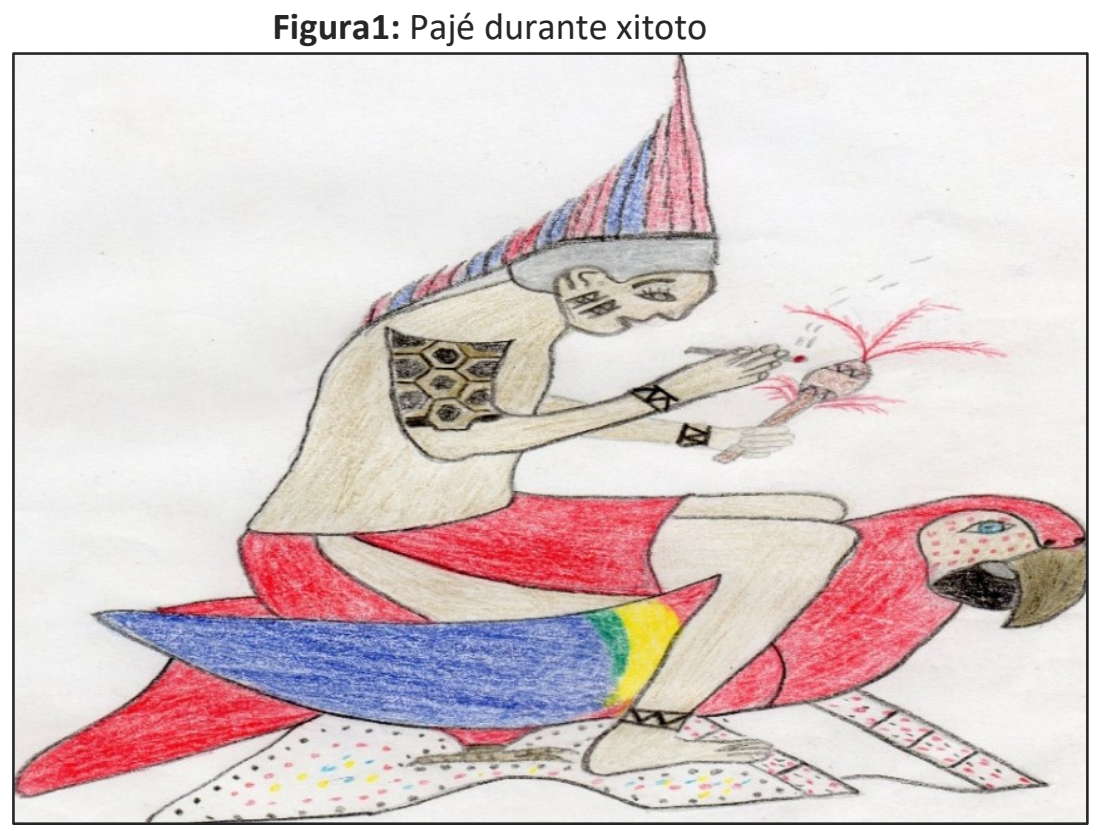

No início do trabalho xitoto, o pajé começa com o assobio, utilizado para chamar os karuãnas, para participarem do xitoto e cantar. O murmúrio, que é de difícil entendimento para as pessoas que estão próximas, recorta alguns momentos do xitoto. $\mathrm{O}$ assopro também ocorre ao ser inserido entre os versos dos pota. A execução dos pota têm a participação apenas da pessoa que fará os trabalhos do pota e do paciente, ao contrário do xitoto que envolve mais pessoas.

Figura 2: Homem executando pota sobre criança

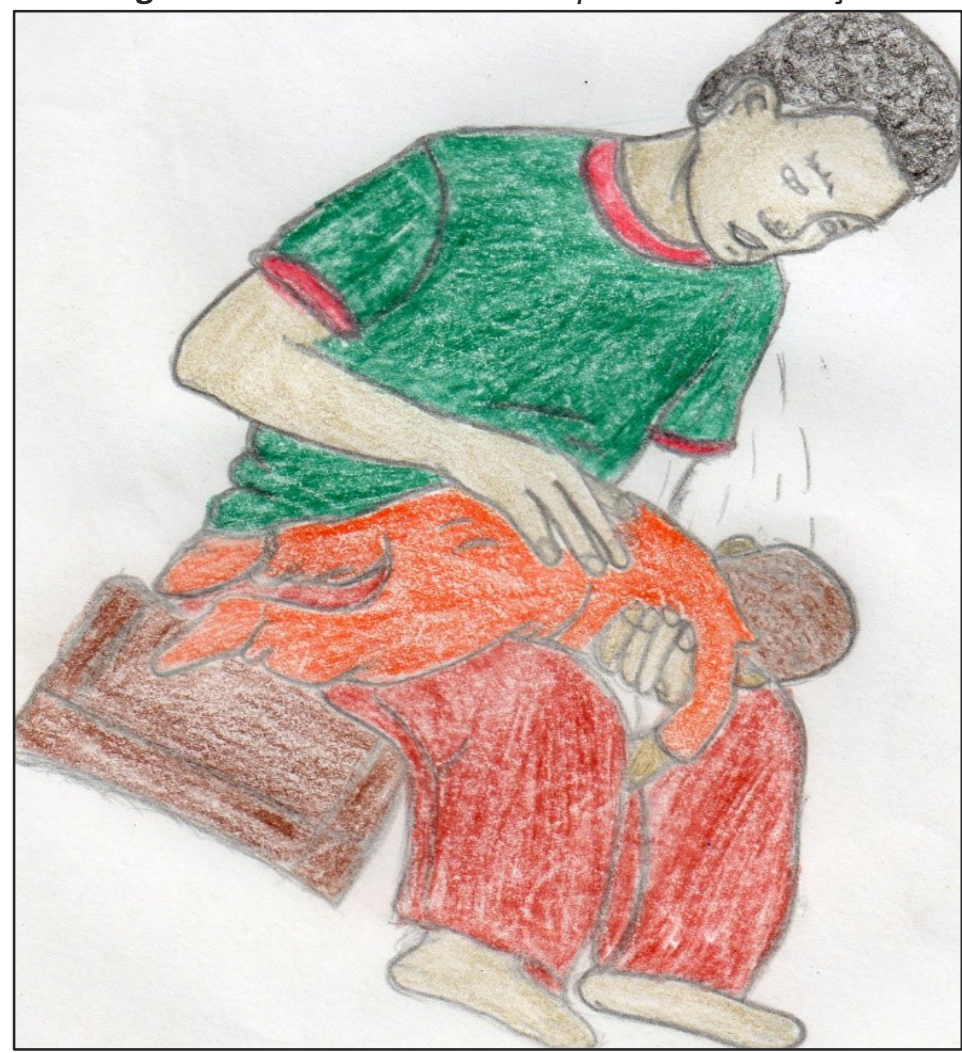


O assobio pode ser executado de várias maneiras. Pode servir para convidar ou chamar os karuãnas para participarem de um xitoto. Para isso, o pajé assovia como se imitasse um pássaro, esse é o chamado para que seus karuãnas estejam presentes. Após a chegada dos karuãnas, o pajé utiliza-se do assobio mais uma vez, agora, para convocar o dono do banco, que faz parte do xitoto. Esse dono pode ser um animal da terra, da água ou uma ave. O assobio também ocorre cortando os potas ('rezas') que fazem parte da cura de algumas doenças provocadas por algum ser maligno. Eles são executados nas línguas originárias antigas, que geralmente é o Galibi Antigo. O murmúrio funciona como espécie de disfarce para que ninguém em volta saiba. Às vezes há essa necessidade. O assopro geralmente ocorre no pota na metade da execução ou no final. Elas direcionam a cura para o paciente ao afastar o espírito que está causando mal ao paciente.

Após essa breve introdução, nas próximas seções tratamos de explorar os significados que podem emergir/aparecer de um pota e dos comentários de um pajé sobre alguns outros pontos sobre as formas do pensamento indígena.

\section{0 canto do Ueio panã: forma e conteúdo}

Nesta seção olharemos para o canto do Redemoinho, que é bastante comum em contexto de Turé. É uma espécie de canto inicial de chamamento de karuãnas para o início do Turé, que é uma grande festa onde há a presença de muitos karuãna.

Figura 3: Representação de um Turé

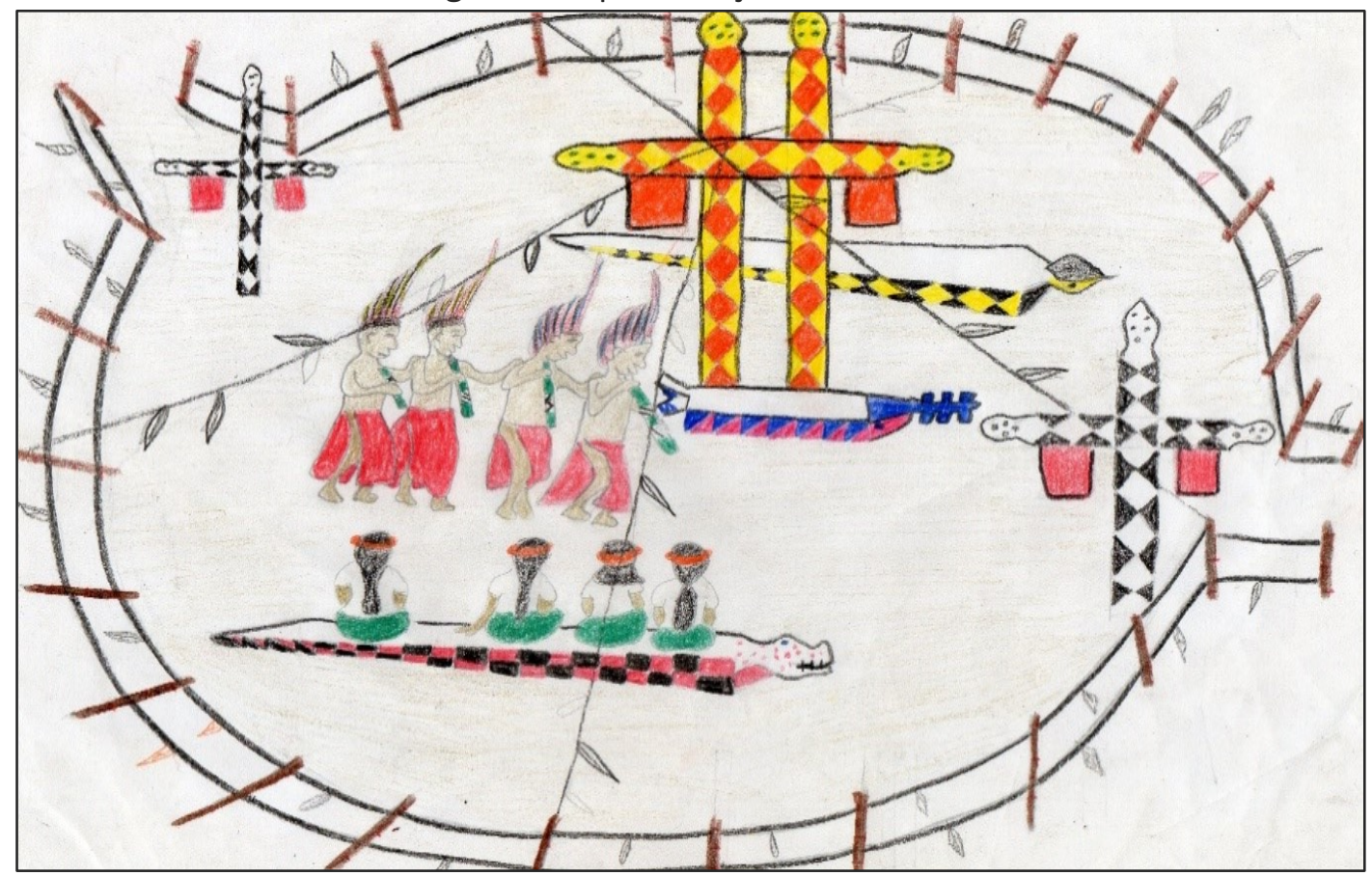

Olharei para o canto do Redemoinho de duas formas: fazendo a tradução literal das palavras do Galibi Antigo para o Português e fazendo a tradução simbólica, ou comentário, das partes que compõem o texto. A partir disso, parto para a entrevista com o pajé Martinho Damasceno, de modo 
a tirarmos dúvidas, sobre como cada um daqueles 'personagens' e 'cenários' que ocorrem a partir desse texto inicial podem se desdobrar em explicações maiores sobre o pensamento indígena a partir de sua poética. Ao final, tentos fazer algumas conexões entre o que se apresenta no texto e a interpretação do pajé que possa revelar alguns aspectos sobre as formas da expressão da poética indígena e do pensamento indígena.

\subsection{O canto do Redemoinho}

\section{Ueio Panã, Kuhãduble, Redemoinho}

Ueio, ueio, ueio panã, ueio, ueio, ueio panã, teiãte, teiãte, teiãte

Sol, sol, sol redemoinho sol, sol, sol redemoinho "teiãte (som da flauta)

Ueio, ueio, ueio panã, ueio, ueio, ueio panã, teiãte, teiãte, teiãte

Sol, sol, sol redemoinho sol, sol, sol redemoinho "teiãte (som da flauta)

Ueio, ueio panã tõtairanã, ueio, ueio

Sol, sol redemoinho fundo da mata sol, sol

Ueio, ueio panã tõtairanã, ueio, ueio

Sol, sol redemoinho fundo da mata sol, sol

Com exceção do som da flauta, todo este canto é entoado em Galibi Antigo. Ocorre geralmente no início do Turé para chamar os karuãna para beberem com os pajés. São apenas três entidades que aparecem: sol, redemoinho da água e o fundo da mata. $\mathrm{O}$ sol, o fundo da mata, e o redemoinho parecem, inicialmente, fronteiras de lugares (mundos) diferentes. O pajé, que é aquele que consegue falar e ir para "lugares diferentes", atravessar e voltar desses mundos, é a melhor fonte para iniciarmos uma conversa que possa nos dizer o que esse pequeno canto pode nos dizer sobre o pensamento Karipuna.

\subsection{A interpretação do pajé}

Entrevistei o pajé Martinho Júnior dos Santos Damasceno, indígena Karipuna, de 33 anos de idade (11/05/1985), morador da Aldeia Indígena Açaizal, às margens do rio Curipi, em na Terra Indígena Uaçá; filho de Catarina dos Santos e Martinho dos Santos Damasceno. Atualmente, ele atua na aldeia Açaizal como cacique e pajé da comunidade. Estudou e finalizou seus estudos de ensino fundamental na Escola Indígena Estadual São Sebastião do Açaizal e concluiu o ensino médio submetendo-se ao Exame Geral da Educação de Jovens e Adultos, realizada no mês de setembro, no ano de 2018, pelo Núcleo de Educação de Jovens e Adultos (NEJA), da Secretaria de Estado da Educação (SEED/AP).

Com a intenção de interpretar o conteúdo do pota do Redemoinho, checar e desenvolver a ideia do que o pota 'diz' tem a ver com a ideia de fronteiras, bolamos algumas perguntas para o pajé Martinho.

Tenho como ideia inicial (talvez eu possa usar a palavra hipótese) que o pajé se coloca nessa posição de 'diplomata dos espíritos', logo, ele vai criar e transmitir em cima dessa natureza dele 
para que ela seja conhecida e mantida (rememorada). Nessa seção vamos costurar a entrevista com alguns comentários que explorem as perguntas deste trabalho. As perguntas estarão em negrito, as respostas do pajé Martinho estarão em itálico e os nossos comentários nesta formatação padrão.

\begin{abstract}
ERDESON: Por que o "fundo d'agua" é tão importante neste verso? Tem karuãna? Qualquer um pode descer?

MARTINHO5: Para mim é a escada onde os karuãnas vem do fundo da água naquele redemoinho, para vir participar do Turé, ele roda vem trazendo. Lógico que ele tem o dono dele, a agua é o dono, onde, tipo aqueles remansos, é tipo vento que dá, que vem aquela força da água, que dá aquele redemoinho que vem que é o Ueio Panã que vem surgindo para vim beber e lógico qualquer uma pessoa pode entrar no fundo da água, mas nessa parte da visão só o pajé que pode se comunicar com esse redemoinho porque é um espírito também, para nós no nosso mundo do pajé ele é um espírito de ser invisível que vem, que tá no nosso meio, só que ninguém pode ver só nós que podemos ver.
\end{abstract}

A primeira afirmação do pajé é a melhor memória e visão de que o fundo d'água e o lado de fora, onde o sol bate, são conectados pelo redemoinho, que é a 'escada' dos karuãnas. Apesar da memória envolver uma coisa ('escada'), o redemoinho em si é um karuãna, ou seja, é espírito, ou seja, está vivo. O pajé também reforça que só ele 'se comunica' com os karuãnas, ou seja, só ele fala a língua dos karuãnas da forma certa.

\title{
ERDESON: A língua dos karuãnas: como se aprende a língua do karuãna?
}

MARTINHO: Se eu fazer um Turé e eu convido, eu deixo meu corpo para eles, eu não vou aprender, eles vão entrar no meu corpo, eles vão usar o meu corpo e eles vão falar, no momento que eles entrar eu já tô falando a língua deles, já no momento que eles vão embora eu já nem tudo sei, porque é eles que vem no meu corpo, eu deixo o meu corpo eles vem entram, eles falam, cantam, bebem daí pronto depois que terminar vão embora e já não sei de nada quase, de algumas coisas eu lembro, de algumas coisa eu não lembro é assim.

Entende-se aqui a ideia de saber de uma perspectiva diferente da Ocidental. Não é o saber 'técnico', aquele que você sabe e 'pronto', o saber falar a 'língua dos karuãnas' é um saber transitório em seu formato. Ele é dependente do corpo do pajé, que funciona como uma 'porta', a própria escada, desse lado do mundo, o nosso mundo. O pajé 'é como' o redemoinho pois ele é a própria 'escada' que traz o karuãna para este lado.

ERDESON: $\mathbf{O}$ que você vê no redemoinho? É gente, espírito, uma coisa? O que é?

MARTINHO: O redemoinho é um espírito de pessoa, o dono da água do redemoinho, é uma pessoa na minha visão que eu vejo como pajé é uma pessoa que é o dono daquilo que quando eu convido ele vem para beber é uma pessoa.

\footnotetext{
${ }^{5}$ Mantive ao máximo a oralidade na transcrição desta entrevista. Esta entrevista foi gravada em um celular Wiko e salva em formato amr e 3gpp, com duração de 31.87. Ocorreu no local aldeia Açaizal na data 14-01-2018. 
O redemoinho visto na perspectiva não-xamânica é apenas um redemoinho, já o redemoinho visto pelo pajé é em forma de pessoa. O karuãna é redemoinho ou gente? Depende de quem vê. ${ }^{6} \mathrm{O}$ pajé é capaz de ver a 'gentitude' do karuãna. Vendo-o (e só o vendo) se comunica com ele.

ERDESON: No início, qualquer um podia tocar flauta? Quem é o dono da flauta? Tem restrição? Qualquer um pode tocar a flauta menos a mulher que não pode assoprar a flauta, porque tem uma regra, a mulher não pode assoprar a flauta devido que ela engravida, aí ela não pode assoprar a flauta. Os rapazes não, qualquer um pode mexer na flauta desde que não come pimenta, se comer pimenta o som da flauta não vai sair bonito, ele tem que saber fazer bem a sua flauta e ajeitar ela. Já a mulher não. É diferente. Ela não pode tocar mesmo na flauta, é uma regra que tem, o dono dele não gosta que a mulher toca na flauta, lógico que ele tem o dono dele. É um espirito de pessoa, é uma pessoa, um karuãna que toma conta de tudo aquilo, quando tu vai buscar ele, tu tem que defumar, fumar lá no meio deles, porque o dono de lá é brabo é um flechador que tem lá é por isso que é fino, quando tu vai tirar essa flauta. É um índio que tá lá. E também quando tu vim de lá, tu vem direto com ele, não entra pitiú7, porque é fino e no momento que tu chega com ele, tu já mete lá naquele local [no laku]. Quando tu terminar com ele, tu já entra com ele dentro do laku, e de lá não pode mais sair de lá não, só vai sair quando terminar o Turé, que já o pajé vai se desfazer, vai tirar aquele karuãna de lá e daí já não vai mais valer de nada, então ele é a peça principal também no Turé, que faz o bonito no Turé são as flautas. E o índio flechador fica até o final, ele é o responsável, porque você convida ele e depois que o pajé se despede ele vai embora e as flautas não tem valia de nada.

Algumas partes são bem importantes. A primeira é que o pajé explica que a figura da pessoa é a de um 'indío flechador'. A segunda parte importante é que você não pode estar com cheiro forte de peixe. Essas duas partes se juntam para explicar por que há essa restrição de cheiro. 0 índio flechador que vem do fundo d'água tem aversão à peixe. Mais adiante o pajé retoma e explica isso de maneira mais detalhada essa repulsa na relação de predação com o igual ou 'do mesmo mundo'.

Outra parte importante é o comentário sobre a finura necessária que se deve obedecer para tirar a madeira para fabricar a flauta. Num dos momentos o pajé dá a entender que a flauta serve para 'flechar' o índio flechador para o laku: "porque é fino[a flauta e a flecha] e no momento que tu chega com ele, tu já mete lá naquele local [no centro do laku, perto do banco do pajé e dos mastros centrais]. Quando tu terminar com ele, tu já entra com ele dentro do laku, e de lá não pode mais sair de lá não".

A flauta traz o karuãna através de seu som, a flecha traz o karuãna como presa, e a flauta não pode ser usada pelas mulheres sob o risco de gravidez. Ou seja, a flauta, em mãos erradas, poderia promover a reprodução física de uma pessoa espírito com uma pessoa do nosso mundo. A

\footnotetext{
${ }^{6}$ Não quero fazer uma análise antropológica ou etnográfica, mas é impossível não remeter essa interpretação às ideias de Eduardo Viveiros de Castro (2004) sobre o chamado Perspectivismo Ameríndio, que seria uma ideia filosófica mais geral sobre Pensamento Indígena. A nossa forma de interpretar as ideias contidas no pota e explicadas pelo pajé são do campo, digamos, mais próximos da 'literatura'. Não pretendem explicar cosmologias e outros aspectos interessantes abordados pela Antropologia. Pretendemos interculturalizar algumas explicações com ideias (epistemologias) ocidentais e minha visão indígena do mundo para multiplicarmos e alcançarmos alguns sentidos.

${ }^{7}$ Ou seja, com cheiro forte associado a peixe.
} 
flauta, na forma-flauta produz o Turé, na forma-flecha produz a caça e na forma-reprodutor pode produzir pessoa com espírito. Essa referência (flauta-flecha?) sempre cria algo.

Não tenho muita certeza, mas acho que posso pensar assim: será que a forma-flauta significa no nosso mundo nascimento de pessoa-espírito, mas no fundo d'água a, então, forma-flecha signifique o inverso, ou seja, a 'morte' ou 'viagem' de alguém? Será que é por isso que é evitada pelas mulheres? Será que essa restrição de gênero, se deve à perspectiva de que a mulher 'gera', daí a restrição a ela da flauta, enquanto, o homem 'caça', daí poder portar a forma-flauta-flecha. Não temos certeza, mas é possível pensar assim. Forma flauta-flecha explicaria a oposição nosso mundo/fundo d'água, a oposição homem/mulher, e até a oposição predador/caça.

\section{ERDESON: Por que é um Índio flechador?}

MARTINHO: Porque ele é o dono, ele que toma conta de lá daquele "sinal" ele que manda, ele que comanda lá eles todos, é por isso que é um índio flechador é ele que tá lá comandando eles todos, ele é o principal, ele é o chefe de lá, ai varia de cada local a onde tem "sinal", porque tem local a onde são outros donos né e lá onde eu vou buscar os meus 'sinal' é um índio flechador que tá lá, que toma conta.

O pajé explica que a ideia de um flechador tem a ideia de comunicação entre 'donos' que, pelo uso dele, significa chefe. Isso reforça a nossa ideia de que o pajé se apresenta como um verdadeiro 'diplomata dos espíritos'.

\section{ERDESON: Para que o cigarro?}

MARTINHO: O cigarro é uma oferenda pra eles, pra defumar, oferecer pra eles e fumar com eles, ai ele vai deixar eles tirar o 'sinal' que não é pra fazer nem um mal, o cigarro é uma oferenda pra eles saber que eles estão fumando com ele, eles estão retribuindo o que ele tá dando pra eles.

Para que todos os leitores entendam essa parte, é que como se a oferenda fosse um presente para agradar um hóspede ou estrangeiro para que você tenha um encontro com ele. É muito importante que esse encontro seja bom, então o cigarro é a nossa oferenda ou presente para o karuãna vir tranquilamente.

\section{ERDESON: De que forma o índio flechador vê as pessoas desse mundo?}

MARTINHO: A forma, eles vê nós, ele não vê as pessoas como humano, eles vê as pessoas como um ser assim um bicho né, que nem um macaco, pra eles todos são macaco, eles não vê a gente como humano, pra eles, são eles que são humanos e nós que somos macacos. Então é por isso que tem que fazer tudo isso, a defumação, pra eles não malinarem ${ }^{8}$ com as pessoas, pra eles nós somos macacos.

O pajé explica que os karuãnas veem as pessoas como macacos, ou seja, como presas. A defumação serve para digamos, mascarar, talvez, essa impressão. O pajé não deixa claro se ele o vê

\footnotetext{
${ }^{8}$ Fazerem algum mal. 
como macaco, ou se ele tem uma espécie de 'roupa' que faz com que ele não seja visto como macaco, mas como gente pelo karuãna.

O pajé vê o redemoinho como gente, se as nossas sequências de invertidas (simetrias e ou inversos) explicarem a forma geral, então é bem possível pensar que o pajé também passa de uma aparência de macaco para gente em relação ao karuãna com quem ele se comunica.

\section{ERDESON: O que o pajé intruso faz com você, você pode fazer com ele?}

MARTINHO: Dessa forma como pajé, tem sempre, tem pajé que vem, outros pajés que vem experimentar pra ver se tu é forte, é existe aquele que quer fazer só maldade, assim se eu to fazendo o meu Turé, sempre vem alguém pra me querer fazer o mal, ai mas logico que eu já to preparado pra ele não vim mexer comigo, eu já to fazendo a minha retribuição com ele, por que se eu tô no meu trabalho eu não gosto que eles vem mexer, porque se eles estão no trabalho deles eu não vou mexer com ele. Mas sempre tem um intruso que não tá nem vendo com isso vem mesmo pra fazer a maldade.

O pajé explica que às vezes outro karuãna quer entrar onde não convidado. Nesse caso, parece que há uma disputa quem vai ser o predador ou a caça naquela relação, que é sempre transitória. Os papeis de predador ou de caça podem ser mudados pelas partes dos dois mundos.

\section{ERDESON: O que o karuãna sente e ouve no momento do Turé?}

MARTINHO: Por exemplo se eu to fazendo o meu Turé, então vai ter a regra, não vai entrar com 'pitiu', porque se tu for entrar com 'pitiu' eles podem se afastar, não vai ser aquela diversão que eles vêm pra fazer, porque eles são pessoas, espíritos que não comem o peixe, no mundo em que eles vivem, eles não comem peixe, tem outros que não comem e não gostam do 'pitiu', ai já vai fazer mal e vão pensar que tão abusando, ou eles derrubam o pajé, ou eles fazem besteiras pra outra pessoa que tá abusando deles, então é por isso a proibição do 'pitiu' na hora da dança, que o cheiro irrita, ele faz mal pra ele, aí pra eles a modo tu tá fazendo um abuso é por isso, no Turé quando tu vai dançar pra ti pegar tudo, entrar lá dentro, tu sempre tem que tomar um banho ou comer primeiro e depois tomar um banho bem, lavar a mão com sabão, corpo bem com sabão pra tirar o cheiro do 'pitiu' pra poder participar da dança, se não ele vai, sempre ou o pajé cai pra não fazer mal pra outras pessoas ou as pessoas, pode acertar em alguém, porque eles não tão só la dentro do laku, o pajé mete pra fora também, que ele não vai ficar só com eles lá dentro, então, é por isso a proibição do 'pitiu' e outras coisas. Nem todo pajé vai suportar o abuso, porque às vezes têm pessoas que faz o abuso quer abusar pra ver se tem certeza mesmo então, é por isso que muitas das vezes tem pajé que não tem paciência e faz besteiras.

O pajé finaliza a última pergunta reforçando a questão dos sentidos na relação com os karuãna. A restrição de cheiro, o cuidado e a forma certa de fazer refletem isso. o karuãna do redemoinho, que mora no fundo d'água, tem repulsa por peixe, pois eles não comem peixe. Aquele que pode ser uma presa nessa relação nunca é o nosso igual, mas sempre a pessoa espírito do outro mundo. 


\section{Uma reflexão sobre a poética indígena: conclusões}

O canto para os povos indígenas representa um dos saberes orais importantes dentro da cosmologia indígena desde sua existência. Esse conhecimento de tradição oral tem uma relação cosmológica, nos sistemas sociais e na vida cotidiana de cada povo e que durante o período colonial esses conhecimentos não tiveram atenção necessária para a manutenção de sua existência.

Por isso, muitos desses saberes nos dias de hoje são investigados pelos estudos linguísticos que somente agora está se apresentando no cenário acadêmico e das pesquisas que reúne diversos e os mais importantes usos da linguagem verbal na sociedade indígena. Estudando sobre as formas e estilos desses saberes etnológicos, nesse sentido além de ser uma tradição oral o canto pode ser considerado uma das formas de repassar esses conhecimentos para as gerações futuras.

Os gêneros narrativos no contexto indígena se caracterizam pela necessidade que os povos têm em se comunicar e expressar algo de sua natureza que são múltiplas na sua vida em comunidade, em que os atos verbais são vários e apresentam, em sua maior parte, repetições e padronização nas suas estruturas textuais e nas suas formas discursivas. As formas discursivas para os povos indígenas se processam em rituais em conjunto da comunidade em momentos particulares de hábitos e práticas socioculturais de cada povo.

Para os Karipuna, povo do Uaçá, os cantos, como formas discursivas de comunicação oral, em seus rituais, para agradecimentos e curas com o sobrenatural, estão presentes na vida cotidiana. A principal atividade desse povo em praticar esses momentos da cultura é através de suas festas tradicionais. O Turé é a festa realizada por este povo como meio de agradecimento a curas, remédios e bonanças que foram promovidas por seres sobrenaturais, onde são feitos cantos pelo pajé realizador da festa e pelos seus ajudantes e participantes do ritual para convidar os karuãnas, que são seres invisíveis, espíritos que vivem em outro mundo, vistos apenas por um pajé.

O pajé é o principal responsável por este ato de chamar, convidar os karuãnas através do canto para participar do ritual da festa que está sendo realizado. A cada canto entoado, significa que um karuãna está chegando ou está sendo convidado para beber a bebida indígena, dançar e se divertir com as pessoas no laku. Para cada karuãna é cantado um canto, ou seja, cada um tem seu verso próprio para cantar ou ser cantado no momento da dança.

Os karuãnas são seres do mundo sobrenatural que podem ser espíritos de pessoas ou animais que vivem nas águas, nas matas, na terra ou do espaço que eles estiverem. Quando são cantados no Turé, o canto de cada karuãna é acompanhado por sons de flautas que são assoprados pelos homens e também pelo som de maracas do pajé e de seus tet dãse, fazendo assim o ritual ficar mais animado e divertido. Entre os Karipuna há também outras formas de se comunicar com o sobrenatural, e em umas dessas formas de comunicação está o pota, que é uma pratica que se é muito utilizado, cantos em tons bem baixinhos, que são realizados para tratamentos de doenças que é provocado por seres sobrenaturais e também pode ser utilizado para fazer malefícios a alguém.

Quanto ao conteúdo do que é dito e representado nos pota, busquei, a partir de apenas um canto, desenrolar alguns significados que essa expressão formal pode criar. Mostrei que é 
importante a ideia de lugar ou de mundo de origem para os karuãna: isso vai determinar como eles se relacionam com os outros seres de outro mundo. O Outro Mundo parece uma espécie de espelho inverso do nosso mundo: no funda d'água não se come peixe (se tem repulsa ao cheiro); a flauta do Turé é uma "flecha" para o karuãna índio flechador (que o prende no laku), mas também pode ser a causa de uma gravidez indesejada, que mistura "gente" deste mundo e "karuãna", se manuseada por mulheres. Ou seja, a flauta pode ser, ao mesmo tempo, instrumento de caça (abate) de um lado e instrumento de criação do outro (gravidez). Ser xamã é muito perigoso. A forma de se comunicar com o Outro Mundo é muito específica: os karuãna somente entendem cantos (formalidade máxima) como nós entendemos a conversa (prosa, ou pouca formalidade.). Qualquer erro pode matar alguém ou nascer alguém indesejado.

Por fim, este foi apenas um exercício de interpretação que teve como objetivo comentar algumas expressões possíveis do pensamento indígena a partir do saber verbal do xamã. Além de ser uma contribuição para a área de Linguagens e Códigos, este trabalho também poderá servir de base para o estudo, conhecimento e discussão das artes verbais indígenas na Educação Escolar Indígena.

\section{Referências}

ARISTÓTELES. Arte Poética. Disponível em <http://www.dominiopublico.gov.br/download/texto/ cv000005.pdf>. Acesso em 14 nov. 2018.

CASTRO, E. V. Perspectivismo e multinaturalismo na América indígena. O que nos faz pensar, v. 14, n. 18, p. 225-254, 2004.

FORTE, J. S. Lang dji Pota-iela: a Língua dos Pota. 2017. Monografia. Licenciatura Intercultural Indígena, Universidade Federal do Amapá, Oiapoque, 2017.

FRANCHETTO, B. Forma e significado na poética kuikúro. Amerindia n. 14, 1989.

GALLOIS, D. T.; GRUPIONI, D. F. Povos indígenas no Amapá e Norte do Pará: quem são, onde estão, quantos são, como vivem e o que pensam? São Paulo: lepé, 2003.

IEPE. O Lago Maruane: conhecimentos tradicionais dos Galibi-Marworno, 2017.

RICARDO, C. A. (Ed.). Povos indígenas no Brasil. Volume 3: Amapá/Norte do Pará. São Paulo: CEDI, 1983.

SILVA, E. B. A língua Parikwaki (Palikur, Arawak): situação sociolinguística, fonética e fonologia. 2016. Tese (Doutorado em Linguística). Faculdade de Letras, Universidade Federal do Rio de Janeiro, Rio de Janeiro, 2016. 